\title{
A Critique on the Application of the Principle of Subsidiarity Concerning Human Embryonic Stem Cell Research in South Africa
}

\author{
Fikile Muriel Mnisi \\ Steve Biko Centre for Bioethics, Witwatersrand University, Parktown, Johannesburg 2193, South Africa
}

\begin{abstract}
Researchers from all around the world emphasize on the enormous possible benefits that stem cells may have for the treatment of diseases. However, this technology is considered morally problematic when the source of the stem cell is from a human embryo. Nonetheless, there is a consensus that of all the types of stem cells, hESC (human embryonic stem cells) are the most promising for particular and important research and therapies. Yet, there are controversial issues regarding the "killing" of the human embryo for stem cell derivation. There are two general ethical conditions that should govern the instrumental use of embryo. One of them, the principle of subsidiarity, which is defined as "a state we have that we have to choose the less contentious means of achieving the intended goal". Based on this principle, we ought only to use hESC when there are no other alternatives, which are less morally controversially. Subsidiarity is based on the assumption that there is something ethically unsound about the use of hESC. However, this principle only makes sense if it is based on consistently upheld views of the moral status of embryo, moreover, the law should also not limit or prohibit hESC research based on this principle. In this paper, I argue - using the South African law for hESC technology-that criterion for deciding which type of stem cells to use should be based on their potential and suitability for advancing scientific knowledge and development of new therapies which will be greatly beneficial in alleviating human suffering.
\end{abstract}

Key words: Principle of subsidiarity, stem cell, human embryo, human embryonic stem cell.

\section{Introduction}

In the last decade or so, stem cell research has emerged as an important field of study due its therapeutic potential, specifically with regards to the cells' malleability and its ability to regenerate. Stem cells are capable of replicating themselves, as well as to repair and replace other tissues in the human body. Consequently, stem cells possess an ability to be manipulated in the laboratory in ways that may change their identity and function, turning it into a number of different types of cells or tissue, making them a powerful tool for research and therapeutic purposes [1]. Stem cells comprises of different kinds or types of cells

Corresponding author: Fikile Muriel Mnisi, Ph.D. candidate, research fields: bioethics or bioethical issues or ELSI (ethics, legal and social issues) regarding hESC regulations and legal framework, as well as other bio-technologies, such as tissue engineering, proteomics and so forth and bio-patents. that are from different types of sources. The types of stem cell sources differ based on their malleability function. The most important sources include: ASCs (adult stem cells), such as neural stem cells, skin stem cells, blood (hematopoietic) stem cells, bone marrow blood and umbilical cord blood stem cells; iPSCs (induced pluripotent stem cells) (these being from ASC (somatic) and induced to behave like hESC (human embryonic stem cells)); and hESC derived from human embryos. The use of hESC for research and therapeutic purposes has sparked some lively debates and ethical controversies, particularly concerning the "killing" or destruction of human embryos to derive stem cells for research and therapeutic purposes.

Additional concerns involve questions whether this type of research is morally acceptable, whether it should be allowed or not, and, if so, under what 
conditions or constraints it should be allowed. Thus, those who view the sourcing of hESC as "killing" regard this type of research as immoral based on the notion that all human embryos are regarded as "potential" human beings. The implication is that the harvesting of human embryos for stem cell research and therapeutic purposes will amount to "killing" a human being, in other words, regarding an embryo as equal to a "fully-developed" human being. In contrast, those who are in favour of hESC research hold the view that these cells are the most promising for particular and important therapeutic and research aims (such as research of early human development: treatment of diseases and afflictions, such as Parkinson's disease, Alzheimer's disease, diabetes, spinal cord injury, stroke, burns, retinitis and organ failure [2]; the ability to grow whole organs). It is hoped that if this can be successfully done, this would alleviate chronic shortages of organs available for transplant, by enabling researchers to grow their own organ supply by means of hESC [3]; drug screening on hESC lines for research on the toxic effects of drugs [2]. This is significant especially for ethical reasons, since this technology could reduce our current reliance on the use of animals in medical research, compared to other stem cell sources.

Devolder [4] is of the opinion that most of the people involved in these stem cell debate, especially those involved in policy-making, opt for a conciliatory position as they usually do not want to fully prohibit hESC research, while also attempting to articulate at least some grounds for the restraints of the instrumentalization and derivation of embryonic stem cells to protect human embryos. This paper analyses and discusses the South African position in an attempt to provide a context for the progression of hESC research and therapy while also protecting the human embryo. I will be using the subsidiarity principle in favour of the hESC and then indicate that a human embryo does not have a "high" moral status compared to its alternatives. In fact, it will be argued that the human embryo has similar moral status as other alternative stem cell sources. This will be followed by a discussion on whether the South African legislation and regulatory environment is in favour or not of hESC research. Furthermore, based on the principle of subsidiarity, I will argue that the law should allow hESC research and provide a supportive context for its development and progress akin to its alternatives.

\section{Background}

Biotechnology is a dual-effect technology; on one hand, it can produce therapies that may be beneficial to society and on the other hand it can also be harmful to society. Therefore, it is vital that policies and regulations are ethically sound and flexible, so that it not only focuses on research, scientific freedom and knowledge, but also on therapeutic endeavours. In addition, it needs to take into consideration the social implications and ethical issue that arise from these various biotechnologies, for example, hESC technology. These ethical issues and concerns must be critically addressed in order for scientists and researchers to duly appreciate the potential detrimental applications of their work and to make informed decisions to either discontinue and/or redirect their work. Similarly, policy and legislation developers need to critically analyse these issues and make ethically sound and morally justifiable decisions regarding hESC technology.

The incorporation of ethical principle, such as the principle of subsidiarity within the laws and regulations regarding hESC research and therapies, may be beneficial if the principle permits the development of ethically justifiable and sound laws and regulations. However, this may not often be the case as the principle may prove to be not plausible for one particular application, for instance with hESC legislation, while being acceptable for the development of another particular legal application. The use of the principle of subsidiarity to argue against the instrumentalization of the human embryo for hESC 
research and therapies need to convincingly argue that the human embryo does indeed possess a "higher" moral status compared to the other stem cell alternatives. Only then can this principle be applied and used within hESC policies, laws and regulations. However, attempts to make use of this principle to argue against hESC research and therapy within hESC policies and laws have not proven to be effective and ethically sound and justifiable. Therefore, I will argue in the next section that human embryo does not possess a "higher" moral status than the other alternatives. As a result, it can be harvested for hESC research and therapy. A section outlining the inconsistent application of this principle within the SA (South Africa) legal regime, in particular regarding hESC research and therapy, will follow it.

\section{Moral Status of the Human Embryo}

Two moral issues are important regarding the harvesting and creation of human embryo for research or therapeutic purposes. The first issue concerns the moral status of the human embryo itself, while the second issues concerns the moral issue relating to the need for egg donors for these applications and how they can be recruited in a morally acceptable manner [5]. Most people accept that human embryos have a moral significance that distinguishes them from all other human cells and for this reason deserve a certain level of protection. However, those with an absolist view hold that the embryo from the moment of fertilization is a person created by God with its own right and with the same moral status as an adult human being. Therefore, an embryo has a "right to be born" as it is a "potential" person. I will now focus on this potentiality or personhood argument of the embryo, which will be based on both the Western moral philosophy, as well as the African moral philosophy (i.e., Ubuntu).

\subsection{Western Moral Philosophy}

The development of the primitive streak has been suggested as a key cut off point, with reference to SA legislation, for obtaining and harvesting human embryos for research and therapeutic purposes. This coincides with the appearance of the surface thickening that marks the first visible organisation of the embryo around 14 days after fertilisation [6]. Corrigan et al. [6] indicated that this cut-off point is used to distinguish between the "pre-embryo" and the embryo. Since, it is possible for the "pre-embryo" to split into two (i.e., the homozygous twins), which implies that the embryo (at 14 days) is not a "person" given that the concept of personhood is often taken to imply indivisibility as individuality. So what distinguishes and makes the embryo a person or have individuality? According to Western philosophical ideas, personhood can be distinguished by possessing both intrinsic and symbolic values.

Devolder [4] held that an embryo (I will not be using the term pre-embryo unless to explicitly distinguish between pre-embryo and embryo as described earlier) has intrinsic values (values in themselves). Based on this, many people accept that it merits the embryo with some special respect and that due to its symbolic value it must be protected. Intrinsic values include the notion that an embryo can develop into a human being (i.e., potentiality) and that it possesses inherent human dignity. Symbolic value includes the impact it has on certain practices in our respect for human life [4] or expressions of societal views that regard embryos as the initial form of human life [5]. Devolder and Harris [7] stated that, the idea of potentiality is central in the ethics of using embryos for research and therapy. Potentiality is the feature that the human embryo possesses that other members of the species do not, namely to ultimately become a complex, intelligent, self-conscious, multifaceted creature typical of the human species, i.e., a "fully-developed" human being. As a result of these features, a "fully-developed" human being can not be instrumentalized or used as mere means to an end, but may still be used as a means to an end. For example, the participants in a clinical 
trial for testing and/or validating a certain drug are used as means but not mere means to a particular end. Similarly, an embryo may also be used as a means to an end, more so since it does not yet possess the characteristics that make a person to be regarded as a person. Based on the principle of personhood, an embryo is neither a self-conscious, intelligent being who is able to make autonomous decisions nor is it able to distinguish between what is good or bad for it. Clearly, the opposite is true for the participants in clinical trials.

Therefore, the problem with the potentiality argument is that it interprets human embryos as morally important beings in virtue of their potential or in having a protectable interest in actualising that potential. However, some examples provided by Devolder and Harris [7] illustrate how argument lacks some logic; one such example is that of an acorn and oak tree, in that an acorn is not an oak tree even though it has potential to be one. Similarly, the argument does not hold true that the mere fact that something has the potential to become something implies that we must treat it as if it has already achieved that potential. Moreover, unless and until we achieved the possibility of immortality, all of us share one important and inexorable potential - we are all potentially dead, but this does not mean that we should be treated as if we were already dead. Hence one could argue that just because a human embryo has the potential to be a human being does not mean it will end or need to be treated as a human being. Only those who are human beings can be treated as such because they are already.

According to Devolder and Harris [7], a second problematic point with regards to the potentiality argument is that it involves the scope of the potential to becoming an adult human being in itself which is supposedly morally important in virtue of that potential. The argument implies that since the zygote is important because it has the potential for personhood, and if that is what makes it a matter of importance to protect and actualize its potential, then whatever has the potential to become that zygote must also be morally significant for the same reason [7], meaning that anything that has the potential to become an embryo will necessarily need to be treated as an embryo and furthermore as a human being. As such, the principle of potentiality and related arguments will also have to include oocytes and spermatozoa and regard them as having the "potential" to become human beings. Ultimately, oocytes and spermatozoa will have to be treated as human beings and given the same protection and respect as a "fully-developed" human being because it has the same moral importance as the embryo, which has the potential to become a human being.

Devolder and Harris [7] indicated that those who value potentiality for personhood do so not because the potential is contained within "one organism" but because it is the potential to become something, this being the actualisation of which has moral importance. Most people who are uncomfortable at the thought of using human embryos for research and therapy usually give the embryo a high moral importance because of this potentiality. However, they usually do not similarly extend the same moral value to oocytes and spermatozoa. Based on the above, I am of the opinion that the Western philosophical notion of personhood based on potentiality does not provide reasonable and justifiable arguments for not being able to harvest and culture human embryos for stem cell research and therapy. I will now proceed to elucidate on the African philosophy views of personhood and whether an embryo is regarded as a person or potential person or not, with specific reference to the African moral principle of Ubuntu.

\subsection{African Moral Philosophy}

Ubuntu as an ethical principle is centred on morality, with the values of Ubuntu concerned with both the character and behaviour of a person within the context of a "community". One of the aims of Ubuntu is to conserve, develop and perfect the humanity of a person and to bring them to self-realisation [8]. Ubuntu as a 
philosophical construct is challenging to define. One such definition is "Umuntu ngumuntu ngabanye abantu" (Nguni language) meaning "A person is a person through other persons". This encapsulates "humanity", "humanness" and even "humane-ness" and expresses respect and compassion to others [9]. Furthermore, Ubuntu promotes qualities of caring, affection, respect, dearness, sharing, sympathy, humanity, humanism, hospitality, community and solidarity amongst others. So, morality according to Ubuntu is intrinsically related to human happiness and fulfilments [8]. Therefore, Ubuntu is based mostly on intrinsic values that define a person. "Umuntu ngumuntu ngabanye abantu"-Umuntu being "a person" would refer to both Homo sapiens, as well as a person based on personhood.

The above view is aptly illustrated in an empirical study by Gade titled "What is Ubuntu? Different interpretations among South Africans of the African Descent" in 2012. ${ }^{1}$ Gade found that many Africans view the concept of Ubuntu as firstly being based on Homo sapiens; everyone born is a human being no matter what race, disability or other characteristic they have. Secondly, it is based on their relationship with others (community), making them a "fully-developed" human being. In other words, one who is self-conscious, intelligent, able to make decisions on their own but mostly show the virtues and values that are regarded as those of Ubuntu. That which is regarded as personhood is also Ubuntu. I will now proceed to unpack this second "personhood" view in more detail.

Personhood or Umuntu onobuntu—a person with personhood - in an African context would mean that a person to be regarded as a person, as opposed to the concept "isilwane" (directly translated as "an animal"), he or she must possess and show the virtues that are regarded as having Ubuntu. It is important to note that the term embryo is not found in any Nguni language.

\footnotetext{
${ }^{1}$ The reference for Gade's paper may be accessed from http://www.philpaper.org/re/GADWIU at the South African. "What is Ubuntu? Different Interpretation among South Africans for African Descent." Journal of Philosophy 31 (31): 484-503.
}

Also, the announcement of any pregnancy is only made after 12 weeks (three months or first trimester) have passed. It is done for both traditional superstitions, as well as reasons that the person who is pregnant is not yet "fully" pregnant prior to that date and a miscarriage or other complications could still happen which may lead to losing the embryo or foetus. Also, note that in most African culture and tradition there is no distinction between an embryo and pre-embryo. This is critical for the debates on personhood of the embryo in a South African/African context.

Metz [10] stated that, "in many African reflections the concept of personhood is moralised to be a person in a true sense by exhibiting good character"; Good character refers to those values or qualities that define Ubuntu. The implication is that an individual can be more or less of a person, self or human being, when he/she exhibits more of the values defined by Ubuntu. Also, the more they become a "person" (i.e., by exhibiting Ubuntu values) the more the one becomes a better person. The ultimate goal of a person, self or human in the biological sense should then be to become a "full" person, a "real" self or a "genuine" human being and to exhibit these virtues. Achieving the state of Ubuntu is entirely constitutional by positively relating to others in a certain manner [10].

Personhood or Ubuntu does not begin at conception and it is not inherent. According to Nussbaum [11] who quoted Nhlanhla Mkhize, "the African view of personhood denies that a person can be described solely in terms of physical and psychological properties. It is with reference to the community that a person is defined". The importance of the community in self-definition is eloquently summarised by Mbiti, 'I am because we are, and since we are, therefore I am". In other words, "it is through others that one attains selfhood" [8]. The implication is that an embryo, based on the principles of Ubuntu, does not possess qualities or virtues that define it as a "person" or a human being. Ultimately, an embryo will have to be born first and then gradually develop into becoming a person through 
its community. Maintenance of solidarity and humanity is very important in an African context. However, equally important is the maintenance of moral goodness and health (both physical and psychological), it will not only determine how one can or will relate to others, but it will also ensure good quality of life. One implication of health being a state of the whole person [8] is that Ubuntu will be in favour of the harvesting and culturing a human embryo for research and therapeutic purposes to ensure this state of health. Moreover, if this technology will offer help to maintain the health and humanity of those that are currently part of the community or society.

In summary, both the Western and African notions regarding personhood do not indicate the values required by an embryo to define or regarded with the same moral status as with a "fully-developed" human being. Therefore, making use of human embryos in research and therapy should not be regarded as immoral or unethical as many have argued using personhood or the principle of potentiality against such endeavours. As illustrated above, these arguments are inherently illogical and morally unjustifiable, and have indicated that an embryo does not possess a "high" moral status.

\section{The Principle of Subsidiarity: In Favour of Human Embryo}

Since both the Western and African views on personhood do not regard human embryo as possessing personhood or Ubuntu, and both not granting the human embryo a "high" moral status, a human embryo may be instrumentalized for stem cell research and therapy. In this section, I will now indicate how the principle of subsidiarity, which is often used by those in opposition to hESC research, can actually be used in favour of harvesting and using the human embryo for research and therapeutic purposes.

The principle of subsidiarity is not a new concept and can be traced back to at least the nineteenth century. Its formulation is more usually credited to encyclical
Quandragesino Amo (Puis XI, 1931) [4], which is also regarded as the Liberty and Catholic subsidiarity notion by De Visser [12], which states the following:

"... just as it is wrong to withdraw from the individual and to commit to the community at large what private enterprise and endeavours can accomplish, so it is likewise unjust and gravely harmful disturbance of right in order to turn over to a greater society of higher rank functions and services which can be performed by lesser bodies on a lower plane. For a social undertaking of any sort, by its very nature, ought to aid the member of the body social but never to destroy and absorb them."

The effects of this principle, is partly to treat state interventions undesirably, at least to the extent that those available alternatives are to be preferred and partly to justify a degree of institutional decentralization. Even though this principle is more and more being used by political parties and has been influential in the EU (European Union) legislation and also in the South African constitutional law and courts as reported by De Visser [12] in his paper. It is now also being applied in stem cell research and therapy. In bioethics the principle of subsidiarity is defined as "a state that we use to choose the less contentious means of achieving the intended goal" [4]. In the context of stem cell research, it means that research on embryos should only be conducted if there are no other suitable alternatives for the same research and therapeutic goal [13]. Furthermore, Pennings and Van Steirteghem [13] mentioned two general conditions that govern the instrumentalization of human embryos: (1) the proportionality principle, according to which the destruction of the embryo should serve important and worthwhile goals and purposes (generally implying to medical therapy); (2) the subsidiarity principle. Both these principles have been used to argue in favour for and against deriving stem cells from human embryos.

According to Pennings and Van Steirteghem [13], one should be able to determine what suitable alternatives are available for subsidiarity to serve as an 
action guiding principle. Suitable alternatives, from a moral point of view, are entities (or material of entities) with a lower status. This principle, in combination with a number of other conditions imposed on research and the limitation to therapeutic goals, is designed to express the respect due to these entities and to establish an order of priority. The suitable alternatives will have to be argued and show reasonable moral justification that they have a lower moral value than that of a human embryo to be instrumentalized for stem cell research and therapy. As I have already argued from both Western and African philosophical perspectives, a human embryo cannot be regarded as a "person" or "potential" person. Therefore, one should view and decide whether the other alternatives (see below) may be used based on the other conditions (namely research purposes) [13], which will then have to be weighed against the therapeutic goals. Moreover, additional factors, such as technical methods (which is simpler or quicker or cheaper for instance), affordability and access to these therapies, is of paramount importance in developing countries and should also be weighed. All these conditions will have to be considered and reviewed before making any decisions and conclusions regarding the ethical justification, or not, and legal prohibitions pertaining to human embryos.

According to Pennings and Van Steirteghem [13], the other stem cell alternatives to human embryos which are suggested by those who use the principle of subsidiarity to argue against using human embryos as stem cell source for research and therapy include the following: (1) animal material; (2) ASC; (3) iPSC. Induced PSCs are the most favoured alternative and have become stem cell rivals of hESCs. In the next section, I will elaborate on the latter two alternatives with specific reference to their moral status and technical conditions to further support the use of the hESC for stem cell research and therapy.

\subsection{ASC (Adult Stem Cell)}

ASC can be derived from a number of cells that can be procured from living or recently deceased children or adults. Unlike hESC, this procedure is relatively uncontroversial and has been carried out for decades for a variety of purposes [14]. It has research and therapeutic potential in that ASC derived from bone-marrow do not contribute to blood cell lineages, but to neural cell types, as well as muscle and liver tissues [15]. In addition, some advantages that ASC exhibit is that they can be easily obtained from a donor and/or a patient's own tissue sample which can then be grown and genetically modified if needed and used for therapeutic purposes. This reduces problems of tissue rejection after engraftment, especially with ASC from the same patient. Furthermore, the many years of experience within the hemo-oncological field of bone-marrow translation also indicates that ASC are not prone to teratoma formation [15]. However, this procedure does have some disadvantages and concerns. The major limitation of ASC is that it is more difficult to produce large scales numbers in culture due to its restrictive differentiation potential [15]. Also, these stem cells may be derived from fetal tissue (as some kinds of ASC can only be found in fetal tissue) and these cells would in turn raise similar ethical objections as for $\mathrm{hESC}$, especially given the harvesting during a later stage of fetal development as opposed to an embryo [14]. As such, the same arguments as for hESC research and therapy regarding embryo destruction, or the fetus in the case of ASC, do not exactly make ASC a better alternative with a "lower" moral status than using a human embryo for research and therapy. Moreover, the technical conditions for ASC research are challenging and difficult at the moment, making ASC less favourable when compared to using a human embryo as a stem cell source.

\subsection{The iPSCs (Induced Pluripotent Stem Cells)}

The limitations posed by ASC have prompted scientists to focus on developing and reprogramming ASC to behave like hESC, especially because ASC gradually loses the ability to turn on the genes that 
allow embryonic stem cells to be versatile and flexible as ASC becomes more and more differentiated and specialised [16]. However, in late 2007, the Yamanaka team in Japan and Thomson team in USA separately announced success in the use of gene transfer technology (or "reprogramming") to produce pluripotent stem cell lines [17]. According to Green [17], this gave rise to a notion that the debate around the use of hESC lines and the ethical controversies brought about the destruction of human embryos for research and therapy has ended. Thus, iPSC seems to have solved two issues and problems linked to hESC, namely the moral issue and the technical challenges [14]. However, I support Green's [17] notion that, iPSC does pose some important ethical issues as it also uses human somatic or biological materials for research and therapeutic purposes. So, theoretically iPSC can not be void of any ethical issues.

It seems however, that iPSC offer more advantages than disadvantages for its application as a stem cell source. One distinct advantage is the fact that this process does not produce totipotent cells; therefore no human embryo is produced or destroyed. This eliminates the moral controversies surrounding the destruction of human embryos for research and therapies. Additionally, iPSC can be dedifferentiated from the somatic cells of the diseased patient, thus reducing issues of graft rejection. Lastly, iPSC, unlike hESC, do not require a supply of human oocytes for which in itself can be problematic to procure [14]. Both the major ethical issues concerning hESC, namely moral status and oocyte supply, seem to be solved by iPSC and this making it an attractive alternative source of stem cells.

However, iPSC also has its own disadvantages and concerns that need to be duly considered. From a scientific perspective, there is a concern whether iPSC lines will be suitable for use in human transplant and cell regeneration therapies. Currently, iPSC exhibit high rates of tumorigenicity (akin to hESC) in mice as a result of the use of a retroviral vector to carry pluripotency-inducing transcription factor, including the cancer related factor c-Myc. As such, iPSC lines cannot ethically be considered for human transplant purposes, but may still be of value for the creation of model lines of disease-related cells [17]. Also, iPSC techniques and therapies may be quite expensive due to the use of retro-virus and reprogramming techniques, making these therapies unaffordable for poor and disadvantaged individuals, as well as of many who are living in developing countries. This lob-sided affordability of iPSC therapies to those in affluent countries raises an ethical concern regarding distributive justice. According to The New Atlantis [14], another concern is the currently unknown consequences between the gene expression patterns of iPSC and hESC. In addition, some concerns around immune rejection have been raised as studies in mice have indicated that iPSC could trigger an immune response, which in turn may cause tissue rejection. It is believed that the reprogramming of adult cells into iPSC is often incomplete, and this can cause iPSC to retrain certain gene expression patterns from their tissue of origin.

Another significant concern is that early attempts to generate iPSC have yielded only a small proportion of successfully dedifferentiated cells, while most cases report reprogramming between 0.001 and $1 \%$ of cells. Techniques that involve less drastic genetic modifications to induce pluripotency tend to be even less efficient [14]. Furthermore, Obasagie and Theung (2012) argued that, intellectual property issues may become an ethical issue for iPSC research and development and may cause the same, if not more, ethical controversies than the hESC. ${ }^{2}$ Currently, property law in the USA seems to favour the interests

\footnotetext{
${ }^{2}$ Obasogie and Theung's paper on "Moore Is Less: Why the Development of Induced Pluripotent Stem Cells Might Lead Us to Rethink Differential Property Interest in Excused Human Cells" is from Standford Technology Law Review, Vol. 16, No. 1, pp. 51-78, which is accessible from http://librarysource.uchastings.edu/repository.Obesogie/Obasog ie\%20and\%20Theung\%20(STLR)\%20Moore\%20is\%20Less.p df.
} 
of the individual in retaining their property law right over the oocyte, spermatozoon or embryo. The "Davis $v$ Davis" case provides an example regarding how the court determined the property right or interest of a "parent" compared to other somatic cells or tissues. The court granted property right of the oocytes, spermatozoa or embryos to the donor(s), while not granting property right of somatic cells to the donor(s). The court's decision means that, somatic cells are regarded to have a lower moral status than oocytes, spermatozoa or embryos, but that the donor(s) of somatic cell tissue(s) have no property right interests in their own biological material, unlike those of the gametes or embryo donor(s).

Obasagie and Theung (2012) further reported that, somatic cells can be induced to produce mice embryos through iPSC. This suggests that at some future point scientist will similarly be capable to induce somatic cells into human embryo, as well as to induce somatic cells to behave like hESC. One can, therefore, argue that iPSC should not be granted a different (lower) moral status than that of human embryos for deriving stem cell. The implication is that the future possibility of manipulating somatic cells to develop human embryos will raise similar, or even more complex, ethical concerns as hESC. This brings us back to the principle of subsidiarity that one should choose those alternatives that are less contentious than hESC. Most researchers who oppose hESC tend to favour iPSC because it behaves like hESC but is regarded as having less ethical concerns (i.e., lower moral status). Nevertheless, as indicated above, iPSC does pose important ethical issues around intellectual property rights and distributive justice. Moreover, there are still significant technical challenges, such as expensive retro-virus reprogramming and time required for somatic cell induction when compared to the harvesting and culturing of the human embryo for hESC, that need to be addressed before this technology can be used on humans. These conditions are problematic in contributing to social discrimination, as
iPSC will seemingly only be accessible to a selective few opulent individuals.

In closing this section, the principle of subsidiarity requires that the alternatives must have a lower moral status and that they have better research conditions than hESC. However, this paper has thus far indicated that neither requirements have been met. I have indicated that the human embryo does not possess a "high" moral status in both Western and African moral philosophies based on the principle of potentiality, i.e., personhood. In other words, the stem cell alternatives have not proven to possess a lower moral status than hESC, or alternatively the human embryo has not proven to possess a higher moral status than these stem cell alternatives. The implication is that $\mathrm{hESC}$ can be used as an equivalent entity to ASC and iPSC for stem cell research and therapy. Another implication is that hESC should be provided with the same opportunity (by law) as ASC and iPSC. Hence, the law should ideally not show to favour any of the alternative stem cells above the instrumentalization of the human embryo for stem cell research and therapies, as there is no moral status difference between these sources. Also keep in mind that the alternative stem cells do not currently have better research conditions for therapeutic goals than hESC.

\section{Legal Status of the Human Embryo in South Africa}

An analysis of the legal system that regulates stem cell research or hESC research in SA will now follow to provide a better understanding of the legal position and regulations regarding the instrumentalization of the human embryo for hESC research and therapy. In this section, I will firstly discuss the constitutional or fundamental rights of the human embryo, especially whether or not it has any constitutional rights that need to be protected. Since the Constitution 1996 [18] is the supreme law in SA, it will also shed light on whether or not an embryo may be used for research and for therapeutic purposes. This will be followed by a 
discussion of the National Health Act [19], which is the main legislative instrument in SA that regulates stem cell research. Note that this paper will not attempt to scrutinise the SA legislation in great details but to merely allude to the main law that regulates stem cell research, specifically how it regulates hESC in comparison to the other stem cell alternatives, moreover, to also indicate how the principle of subsidiarity can be applied within the legal regime in order to regulate technologies (for example) and in this instance hESC technology.

\subsection{Constitution of the Republic of South Africa, 1996}

"Killing" of the human embryo has been the ethical controversy regarding the using of human embryos for research and therapy, making this technology seemingly unethical and morally unacceptable. However, what is important is to understand whether or not using an embryo for research and therapy does actually legally equate to "killing", since many who oppose this technology seem to think. According to South African law, a person must have lived and breathed and their life taken away and their breath stopped purposefully in order to actually kill someone. With that said, Section 11 (Right to Life) of the Constitution is the foundation of what has the right to life and the right to live, and this section will then provide protection to it. This Section includes only those human beings who are alive and breathing, starting from new born babies and which also includes those babies that were born and lived and breathed for a short time and then passed away after birth. However, the important proviso is that they should have been born alive and have breathed for them to be protected by Section 11. The implication is that Section 11 excludes human embryos as they were never born, never lived and never breathed, even for just a couple of seconds.

Other important sections concerning human embryos based on the ethical debates are those that protect equality (since many who are opposed to hESC regard the embryo as equal to human beings) and dignity (research is regarded as violating the embryo's dignity). Section 9 of the Constitution protects equality and regards everyone as equal before the law, whereas Section 10 protects human dignity and regards dignity as an inherent right that a person would be born with. However, both these sections cannot protect the human embryo because for both sections to be effective, an embryo has to be fully developed and be born first; these sections cannot protect it while it is in its pre-development stage. It is thus clear, that Sections 9-11 of the Constitution do not provide the embryo with any constitutional rights and protection. However, Section 36 (Limitation of Rights) of the Constitution indicates constitutional limitations that may be of paramount importance for human stem cell technologies.

Section 36 states that, the Rights in the Bill may be limited based on human dignity, equality and freedom, meaning that if and when any of those three rights are violated, that particular thing, in this case hESC research and therapy, will necessarily have to be limited by certain restrictions or outright prohibited. However, such a violation will have to be on a living person or society. A human embryo is not subject to the limitation in this section because it is not legally a person. The one implication is that a human embryo cannot be violated based on human dignity, equality and freedom. Another implication is that a human embryo may be instrumentalized for stem cell research and therapy; as such actions do not violate any constitutional rights and protections.

\subsection{The National Health Act (NHA) (No. 61 of 2003)}

The Choice on Termination of Pregnancy of Act, 1996 [20], Section 2(1) allows the termination of a pregnancy up to 12 weeks of gestation period. This law indicates that from the time of conception to 12 weeks gestation the embryo (as defined by the NHA: "a human offspring in the first eight weeks from conception") is not regarded as a human being and hence Section 11 of the Constitution does not protect 
the fetus (as defined by the Regulation Regarding the Use of Human DNA, RNA, Cultured cells, Stem Cells, Blastomeres, Polar Bodies, Embryos, Embryonic Tissue and Small Tissue Biopsies for Diagnostic Testing, Health Research and Therapeutic: "human offspring from eight weeks after conception until birth") but the pregnant female. This Act provides a guideline to what can be legally regarded as a human being even though it does not specifically deal with hESC research or stem cell research in SA. However, Chapter 8 of the National Health Act (NHA) (No. 61 of 2003) is the main legislative reference point regarding stem cell research, including the use of hESC. Section 57 of this Act is titled "Prohibition of Reproductive Cloning of Human Beings" and is of paramount importance for hESC research. This section states the following:

(1) A person may not:

- manipulate any genetic material, including genetic material of human gametes, zygotes or embryos;

- engage in any activity, including nuclear transfer or embryo splitting, for the purpose of the reproductive cloning of a human being;

(2) The Minister may, under such conditions as may be prescribed, permit therapeutic cloning utilising adult or umbilical cord stem cells;

(3) No person may import or export human zygotes or embryos without the prior written approval of the Minister;

(4) The Minister may permit research on stem cells and zygotes which are not more than 14 days old on a written application and if:

- the applicant undertakes to document the research for record purposes;

- prior consent is obtained from the donor of such stem cells or zygotes;

(5) Any person who contravenes a provision of this section or who fails to comply therewith is guilty of an offence and is liable on conviction to a fine or to imprisonment for a period not exceeding five years or to both a fine and such imprisonment;
(6) For the purpose of this section:

- "reproductive cloning of human being" means the manipulation of genetic material in order to achieve the reproduction of human beings and includes nuclear transfer or embryo splitting for such purpose;

- "therapeutic cloning" means the manipulation of genetic material from either adult, zygotic or embryonic cells in order to alter, for therapeutic purposes, the function of cells or tissues.

A close analysis of Section 57 reveals some subsections actually have nothing to do with human reproductive cloning while everything within the Section is under prohibition of human reproductive cloning. In Section 57(1), the use of the word "may" is already confusing as though reproductive cloning of human being is discretional; the use of words such as "should not" would have been more directive. Moreover, what is important to note in this section is that it only permits the use of IVF (in-vitro fertilisation) embryo not exceeding 14 days with a consent and permission from the Minister, but does not allow or prohibits (by default) the creation of embryo by IVF and SCNT (somatic cell nuclear transfer) procedures for research purposes. Neither is there any mention of creating and using hybrids or chimeras for hESC research. Furthermore, Section 57(2) only includes adult or umbilical stem cells, while not mentioning zygotes and embryos, for therapeutic purposes. In contrast, the definition of therapeutic cloning (Section 57(6)(b)) does actually refer to adult, zygotic and embryonic cells, which then excludes hESC for therapeutic cloning (i.e., SCNT therapy), or not explicitly direct about the use of hESC therapy. The implication is that Section 57 of the NHA does not provide a supportive environment for the growth, development and progress of hESC research in SA; also, it clearly favours the use of ASC and umbilical cord stem cells.

It should be noted that some of the above-mentioned loopholes in the NHA were later addressed through the regulations that supplement this Act. These regulations 
are the following: Regulation Regarding the use of DNA, RNA, Cultured Cells, Stem Cells, Blastomeres, Polar Bodies, Embryos, Embryonic Tissue and Small Tissue Biopses for Diagnostic Testing, Health Research and Therapies (No. 29526), and Regulations Regarding Artificial Fertilization and Related Matters (No. 29527). However, neither one of these supplementary regulations address other alternative ways for harvesting human embryo for research and therapeutic purpose apart from what has already been mentioned within Section 57 of the NHA. The regulations inter alia corrected some confusions regarding the definitions of terms found within the Act but do not fully address the loopholes that were found within the Act. Ultimately, the South African legal regime still has significant gaps, restrictions and prohibitions when it comes to hESC research and therapy. These gaps need to be addressed and resolved before $\mathrm{hESC}$ research can develop and progress.

\section{The Principle of Subsidiarity in a South African Legislative Context}

The NHA in South Africa seems to favour ASC, albeit this is by default (I am using the NHA as an example of how the principle of subsidiarity can be applied even though this was done by default in this instance), but does not directly include iPSC, although one can argue that it indirectly does since iPSC is an improved version of ASC. However, the NHA seems to imply that the human embryo as a source of stem cell for research and therapy has a "high" moral status when compared to ASC in allowing ASC to be used for stem cell research but not human embryos. Also, this suggests that legislation regards ASC as legally less contentious than hESC. Such an application of the principle of subsidiarity to favour the alternative stem cell sources is problematic. One implication is that it will decrease the likelihood of scientific growth and development of stem cell research and therapies in SA. According to Pennings and Van Steirteghem [13], the major problem with applying the principle of subsidiarity in ASC compared to hESC is that, one cannot predict with a reasonable degree of certainty which model are the most promising to reach the desired research or therapeutic goals. In fact, this limited knowledge greatly weakens the usefulness of the principle. One possible solution for this situation is that hESC technology should be legally given the opportunity to scientifically establish the proofs and facts on what it can "possibly" offer from both the research and therapeutic perspectives. ASC and/or iPSC may very well be found to be appropriate for specific purposes in research and therapy, whilst hESC may be more appropriate and/or effective in other areas. Ultimately, hESC and the alternative stem cell sources may prove to complement one another and help alleviate human suffering in the process.

Ideally, the principle of subsidiarity will only function well (in-expressing moral status) in the case where all the alternatives stem cell technologies are equally effective for the intended purpose. However, in the present SA context this is not the case and researchers and scientists are in an untenable position where they are required to demonstrate that $\mathrm{hESC}$ is better than the alternative stem cell sources, but are legally not allowed to scientifically investigate and produce evidence for hESC potential. As indicated in Section 57 of the NHA, 14 days supernatant IVF embryos and fetal tissues are the only sources permitted to be used for hESC research. However, these sources for deriving human embryo for hESC research and therapy are not sufficient to demonstrate the therapeutic potential of hESC for public health. Therefore, the law, specifically the NHA, needs to make provision for such research to be conducted in a legal and ethical manner.

The argument that the human embryo has a "higher" moral status than ASC or umbilical cord blood stem cells is problematic within a South African context. Especially since in the African culture the umbilical cord is required to determine where one's "roots" are; In other words, where your umbilical cord is that is 
where your "cultural roots" are believed to be. This can be argued to culturally place the umbilical cord at a "higher" moral status or value than the human embryo. Why then is that the Choice on Termination of Pregnancy Act (TOPA), 1996 allows the termination of a pregnancy and per implication the destruction of a "high" moral status human embryo up to 12 weeks when the NHA places a 14-day restriction and prohibition on the use of human embryo as source of hESC for research and therapy? This means that the TOPA allows legal "killing" or using of a much more developed "potential" person, i.e., a fetus (up to 12 weeks), while the NHA legally prohibits the use of a human embryo after 14 days. Pennings and Van Steirteghem [13] stated that, it makes one wonder whether those who oppose the derivation of stem cell from human embryos are truly interested in the comparison of the efficacy of the different stem cell types in a "fair" and ethical manner. Also, that the opponents of hESC seem to use the principle of subsidiarity merely to postpone, or even ultimately completely prohibit hESC research.

The current situation in which the South African law favours umbilical cord blood stem cells and other iPSC without rigorous ethical investigation and scientific proof suggests that the law clearly favours ASC to hESC for research and therapy, albeit by default. However, the above sections indicates that the legal system has taken a double standard position with regards to the moral status of the human embryo by allowing both IVF procedures and the termination of pregnancy while opposing the derivation of stem cells from the human embryo for hESC research and therapy, as well as creation of human embryo for research and therapeutic purpose only by IVF and SCNT techniques. Thus, it seems that policy-makers and legislators to the idea of hESC research and therapy introduce this principle (even by default) as an illogical way to halt and prohibit hESC research and therapy. I am of the opinion that such a logically unchallenged position will prohibit a "fair" and ethical debate regarding the instrumentalization of human embryos for stem cell research and therapy. Also, it will continue to legally favour hESC alternatives to provide health and healthcare resources for public healthcare, all the while when not being based on what is morally acceptable in SA from both Western and African philosophical perspectives. From a scientific perspective, one type of stem cell source for the improvement of health and healthcare resources and the alleviation of diseases and disorders is not sufficient. Thus, ideally both the alternatives and hESC technologies should be used together as resources for stem cell research and therapy to overcome the current health burden in South Africa and Africa.

\section{Conclusions}

This article attempted to indicate how the principle of subsidiarity could be used in favour of the instrumentalization of the human embryo. Thus, based on the definition of this principle and the moral status of the human embryo as argued, human embryo did not indicate to possess a "high" moral status and can, therefore, be used for research and therapeutic purposes. This article further indicated how the South African law has unfairly regulated hESC technology by applying (by default) this principle. Even though, De Visser [12] stated that, "the general principle of subsidiarity should play a role in law-making, i.e., drafting and adopting of laws, since the Constitution intends that this principle be recognised by the Government". However, the current application of the principle of subsidiarity within the South African legal system to regulate stem cell technologies has invariably resulted in unfair and unethical regulations of stem cell technologies and not used for the benefit of society, as it should. Thus, this principle is only valid when applied appropriately and with scientific foundation and moral justifications to support it. An appropriate and ethical application of this principle will provide legal flexibility and scientific and medical progression of stem cell research, specifically by 


\section{A Critique on the Application of the Principle of Subsidiarity Concerning Human Embryonic Stem Cell Research in South Africa}

allowing the instrumentalization of all stem cell sources.

\section{Acknowledgments}

The author declares that they have no competing interest.

This paper arises from a research done towards the authors' Ph.D. under the Steve Biko Centre for Bioethics at Witwatersrand University. I would like to thank my supervisor Dr. Kevin Behrens from the Steve Biko Centre of Bioethics for his support and critical comments on earlier drafts of this manuscript and through the writing process. I would like to also thank Dr. Braam Hoffmann from Tshwane University of Technology, at the Department of Biomedical Sciences, for his comments concerning the final draft of the paper.

\section{References}

[1] Knowles, L. P. 2010. "What Are Stem Cell And Where Do They Come From?." Stem Cell Network. Accessed September 11, 2013. http://www.stemcellnetwork.ca.

[2] DeWert, G., and Mummery, C. 2003. "Human Embryonic Stem Cells: Research, Ethics and Policy." Human Reproduction 18 (4): 672-82.

[3] Moller, M. S. 2008. "Human Embryonic Stem Cell Research Justice and the Problem of Unequal Biology Access." PED-MED 3 (22): 1-13. Accessed May 13, 2014. http://www.peh-med.com.

[4] Devolder, K. 2005. "Creating and Sacrificing Embryos for Stem Cells." Law, Ethics and Medicine 31: 366-70. Accessed September 11, 2013. http://jme.bjm.com/content/31/6/366.full.html.

[5] Dondorp, W., and Der Wert, G. 2005. Embryonic Stem Cells without Moral Pain?. Ethics \& Health Monitoring Report, 1-34. Accessed September 11, 2013. http://www.ceg.nl/uploads/publicaties/Embryonic_stem cells_without_moral_pain.pdf.

[6] Corrigan, O., Liddell, K., McMillan, J., Stewart, A., and Wallace, S. 2006. "Ethical, Legal and Social Issues in Stem Cell Research and Therapy." Cambridge Genetics Knowledge Park, March 2006, 1-25. Accessed September 12, 2013. http://www.cgkp.org.uk.

[7] Devolder, K., and Harris, J. 2007. "The Ambiguity of the Embryo: Ethical Inconsistency in the Human Embryonic
Stem Cell Debate." Metaphilosophy LLC and Blackwell Publishing Ltd. 38 (2-3): 153-69.

[8] Murove, M. F. 2009. African Ethics: An Anthology of Comparative and Applied Ethics. KwaZulu-Natal: University of KwaZulu-Natal Press, 63-84.

[9] Olinger, H. N., Britz, J. J., and Olivier, M. S. 2005. "Western Privacy and Ubuntu-Influence in the Forthcoming Data Privacy Bill." CiteSeerX. Accessed October 29, 2013. http://mo.co.za/open/ubuntu.pdf.

[10] Mertz, T. 2010. "African and Western Moral Theories in a Bioethical Context." Developing World Bioethics 10 (1): 49-58.

[11] Nussbaum, B. 2003. "Ubuntu: Reflection of South African on Our Common Humanity." Reflections 4 (4): 21-5.

[12] De Visser, J. 2010. "Institutional Subsidiarity in the South African Constitution." Stellenbosch Law Review 21 (1): 90-115.

[13] Pennings, G., and Van Steirteghem, A. 2004. "The Subsidiarity Principle in the Context of Embryonic Stem Cell Research." Human Reproduction 19 (5): 1060-4.

[14] The New Atlantis. 2012. A Journal of Technology \& Society, No. 34, 1-146. The New Atlantis. Accessed January 16, 2014. http://www.thenewatlantic.com/.

[15] Oduncu, F. S. 2003. "Stem Cell Research in Germany: Ethics of Healing vs. Human Dignity." Medicine, Health \& Philosophy 6: 5-16. Accessed September 12, 2013. http://link.springer.com/content.pdf/10.1023\%2FA\%3A1 022585217710.pdf.

[16] The National Academies. 2005. "Understanding Stem Cells. An Overview of the Science and Issue from the National Academies." The National Academies. Accessed March 7, 2013. http://www.national-academies.org/.

[17] Green, R. M. 2009. "Ethical Considerations." In Regulations and Ethics. Accessed September 12, 2013. http://ac.els-cdn.com/B9780123747297000664/3-s2.0-B9 780123747297000664-main.pdf?_tid=d1b98e32-1ba9-11 e3-8ffa-00000aacb362\&acdnat=1378990373_7a7e35346 1 abd14f6d368664ee95bd0d.

[18] Government of South Africa. 1996. The Constitution of the Republic of South Africa Act 1996 (No. 108 of 1996). Government of South Africa. Accessed March 5, 2013. http://www.info.gov.za/documents/constitution/1996/a10 8-96.pdf.

[19] Government of South Africa. 2003. National Health Act 2003 (No. 61 of 2003). Accessed January 5, 2013. http://www.info.gov.co.za.

[20] Government of South Africa. 2008. Choice on Termination of Pregnancy Act 1996 (No. 92 of 1996 amended 2008). Government of South Africa. Accessed July 1, 2014. http://www.info.gov.co.za. 